SCHOLARS: Journal of Arts \& Humanities Print ISSN: 2773-7829; e-ISSN: 2773-7837

eJournal Site: www.cdetu.edu.np/ejournal/

- Peer-Reviewed, Open Access Journal

- Indexed in NepJOL; Star-Ranked in JPPS

Central Department of English

- Permanently Archived in Portico

Tribhuvan University

Kirtipur, Nepal

URL: www.cdetu.edu.np

Theoretical/Critical Essay Article

DOI: https://doi.org/10.3126/sjah.v4i1.43056

\title{
The Tamangness as a Cultural Trope: A Rhetorical Analysis of Works by the Tamang Poets
}

\author{
Kumari Lama \\ Department of English, Tribhuvan Multiple Campus, Palpa, Nepal \\ Corresponding Author: Kumari Lama, Email: klama54@gmail.com
}

\begin{abstract}
The paper critically analyzes the Tamangness as a trope of cultural consciousness and dissidence in the selected works by the contemporary Tamang poets. I have discussed the contemporaneity in relation to the 2006 Democratic Movement, which brought about a radical transformation in the socio-political consciousness of marginalized communities. In this regard, I have chosen six representative contemporary Tamang poets who have written in Nepali language for textual analysis of the issues that correspond with the Tamangness and its marginalization. The paper has also overviewed the Tamang literary history since it reifies the systematic development of Tamang consciousness. To discuss the Tamangness, the paper examines the Tamangness through the cultural tropes such as symbols and dissenting voices portrayed in the contemporary Tamang poems. I have employed the fundamental theoretical debates of cultural tropes to examine the Tamangness in the selected poems in which the marginalized Tamang community's resisting voices are put upfront, applying a rhetorical analysis as an approach to the Tamang poetic texts.
\end{abstract}

Keywords: Tamangness, marginalized group, cultural tropes, rhetorical analysis, dissenting voice

\section{Introduction}

The paper critically analyzes the Tamangness in the contemporary Tamang poetry, concentrating on cultural tropes as the poets articulate their identity as well as the voice of resistance. To discuss these cultural tropes, I have undertaken six poems by the contemporary Tamang poets for rhetorical analysis. Even though the contemporaneity covers a wider-period of time, the poems written after 2006 Democratic Movement of Nepal have been selected for analysis. The movement holds great importance in Nepal's history since it has implanted consciousness into each marginal community including Tamangs that was the starting point for unearthing of multifarious marginal issues. As a result, the Tamang poets started overtly raising the issues of their community such as

Article History:

Submitted 15 November 2021

Revised 30 December 2021

Accepted 21 January 2022

\section{Copyright Information:}

Copyright 2022 (C) The Author(s). The publisher may reuse published articles with prior permission of the concerned author(s). The work is licensed under a Creative Commons Attibution 4.0 International License (CC BY 4.0).

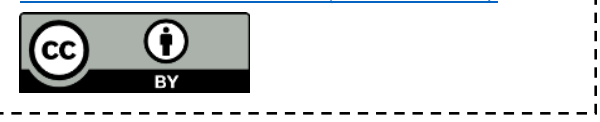

Volume 4, No. 1, February 2022 [pp. 65-76] 
identity, cultural values and the oppressive history of their marginalization.

Since the oral tradition remains at the center of Tamang community, the Tamang intellectuals have adopted writing practices very latterly. Among several factors, their marginalized position and educational deprivation are responsible for undertaking this means. Due to lack of written documents, their history has been limited to their lived experiences, which are expressed in the form of myths and stories. They are orally transferred from one generation to another. Even in such a vulnerable situation, the Tamang descendants have preserved lots of folk songs and stories, cultural narratives and mythological stories. Many Tamang writers have collected folk and mythological stories and published them. In regards to the beginning of documenting Tamang literature, the linguist Amrit Yonjan-Tamang claims, the "collection of Tamang literary materials have started only in 2045 BS [1988-1989]" (32). It clarifies the fact that the Tamang community does not have a long history of written documents. It has taken almost a decade for Yonjan-Tamang to categorize the collected materials and publish them. He has managed to publish a book titled Tamang Prakasanko Bikas ("Development of the Tamang Publications") in 1998-1999, which has become the major attempt to survey Tamang literature.

The Tamang people were systematically excluded by the state. They have come across the time when they were even not permitted to write their surname "Tamang." Their identity was totally squeezed by the orders of Rana rulers and named them as "masinyamatwali" ("Alcohol drinkers"). In this case, András Höfer reveals that in document from 1769, the Murmibhotiya are mentioned as a caste belonging to the "Enslavable Alcohol-Drinker" (qtd. in Acharya 125). Since Jung Bahadur Rana's Muluki Ain ("The Law of the Nation") 1854 has categorized the Tamang community as 'Enslavable Alcohol-Drinker, they naturally became 'murmibhotiya.' In fact, they lost their caste 'Tamang' and named something else as per the whim of the Hindu authorities. They had to struggle and wait for almost eight decades to get back their caste (Höfer 125). Surrounded by such exploitative measures of the Hindu rulers, there was a meagre chance of raising consciousness of Tamang people through writings. Though there were a few Tamang writers who wrote poems in the Tamang language in around 1959, which could not come out in the form of anthology. Bhimraja Lama was the first writer to publish Tamang Burnamala ("Tamang Alphabets") in 1973, which took Tamang literature to the modern era (Yonjan-Tamang 40). However, in India, the Indian Nepali Tamangs of Darjeeling and Sikkim had already published books in the 1960s. YonjanTamang has edited a book titled Nepal Bahiraka Tamang Wangmaya ("Tamang Literature in the Diaspora") in 2012 in which he has mentioned that Buddhiman Tamang had already collected folk literature in 1956 whereas Jangbir Bomjan and Harka Bahadur Pakhrin published the first collection of Tamang songs in 1962 (3). It shows that Tamang literature was written, published and became a part of Tamang intellectuals in Darjeeling since long whereas the strict rules of Rana and Shah regimes obstructed the Tamangs to flourish their creative activities in Nepal.

Even though the 1990's constitution provided equality and freedom for each member of the society, it kept ample space to control people through the so-called mainstream language and religion. Similarly, the re-establishment of democracy and new constitution could not abundantly benefit the Tamang community. They could feel no space even in the new socio-political system. Nonetheless, the establishment of multiparty democratic system in Nepal has somehow enhanced consciousness of each marginal community. As a result, they started writing and voicing against the power blocs. The communist leaders like Nirmal Lama were in continuous resistance since long. The important thing was that the new constitution allowed the freedom of 
expression for the public, which instigated all those suppressed voices to come on the surface. Gradually, the Tamangs and other indigenous groups became more conscious about the issue of identity and freedom. The identity issue entered more intensely into the indigenous communities mainly after the 1990s (Yonjan-Tamang 136).

Subsequently, the newly developed consciousness guided the Tamang literary persons to raise the issues of their community. The educated and aware Tamang writers became more vocal for their rights, which accelerated after the 2006 Democracy Movement. This historical movement of the new millennium became the turning point in Nepali history that kindled the consciousness of each and every marginalized community. Afterward, each dominated caste, class and gender came forward with their collective voice for identity, equality and freedom. Each peripheral communities including the Tamangs have realized the importance of their distinct cultural values. Now, the Tamang writers and intellectuals have raised the distinct voices of dissidence and claimed their identity through their creativity.

The Tamang community has travelled a long arduous journey to establish their cultural identity, which equally integrates the significance of their mother tongue. Acknowledging the importance of writing in the mother tongue, many Tamang writers have written both in Tamang and Nepali language simultaneously. As an outcome, Tamang literature has thrived in terms of the issues that they have raised in their writings. The Tamang writers and researchers are involved in documenting their painful past, which can be helpful to impact the development of their consciousness. Mostly, they are focused to unearth the hidden history and make it useful for the coming generations. They are equally concerned for their identity, space, equality and freedom within the existing power structure.

In this paper, the ideas of Tamang linguist Amrit Yonjan-Tamang have been acknowledged as the foundation of the concept of Tamangness. The major thrust of his ideas was aimed at the revival of organic socio-cultural values, which is possible through creative writing. He was in favor of creating Tamang literature (30). Against this backdrop, this paper has chosen six contemporary Tamang writers. They include Laxmi Rumba, Muktan Theba, Raju Syangtan, Rawat and Phulman Bal. The major concern of the paper is to explore the Tamangness, which denotes the Tamang cultural values and its identity issues, especially raising the voice of the community. There is a lack of literature about the Tamang community. This lack has inspired this researcher to work on this area of study that includes the Tamang literary history and its reviving efforts by the Tamang poets. To meet this objective, this paper has attempted to do a rhetorical analysis of the selected poems by the Tamang poets, delving into the Tamangness of them.

\section{The Rhetoric of Tamangness: A Marginal Issue}

The Tamang community holds unique cultures, values and beliefs that categorize this group as one of the indigenous communities of Nepal. Like other indigenous communities, it has suffered atrocious history of marginalization. Over the past two or three centuries, the Hindu-based rulers have systematically imposed their socio-cultural and religious values on the indigenous communities including the Tamang community. This imposition has not only spoiled the indigenousness of these communities, but also hegemonized, enslaved and dominated them as marginal subjects.

Jung Bahadur Rana's Muluki Ain validated the caste system and social values based on the Hindu system. According to this system, every caste and community was compelled to follow it. It was the same law that officially slit the Tamang's status when it named them 'masinya matwali' and initiated their marginalization. The Rana's country law enforced the Khas language in each nation to thrive on the Hindu culture since each 
ethnic language implicitly or explicitly has to articulate their cultural values rather than being merely a means of communication. It was the main reason for many social thinkers to consistently claim if a language is lost, the whole cultural norms and philosophy of life of a particular community gets threatened. As a result, the Hindu cultural hegemony marginalizes everything, including the Tamang community and its language and cultural values. In this process, the Rana and Shah rulers adopted a systematic Hinduization of indigenous communities. For instance, Chakka Bahadur Lama's case comprehensibly exposes the systematic imposition of Hindu language on the ethnic communities as he claims, "My Lama father had named me Chewang. However, my school teacher renamed me Chakka Bahadur Lama" (227). In this way, a rigid Hindu teacher got rid of his unusual and uncomfortable ethnic name by renaming and adding Hindu flavor as per his comfort. Kamal P. Malla's argument sheds light on Lama's victimization when he points out the fact that the decision-makers in Nepal have always been more keen to show their patronage of Sanskrit than of Nepali languages (285). As a result, the teacher, who inculcated the decision-makers' ideology could not hold for a second before renaming a Tamang boy's name. It unveils the authoritative power of the Hindu rulers that can change the whole process of social phenomenon.

Ever after the 1990 restoration of democracy in Nepal, there was not significant changes in the situation of indigenous communities of Nepal. In particular, the Tamangs were attributed with negative characteristics such as aggressive, uneducated and pigheaded. In the similar manner, black people were associated with negative characteristics attached to their skin color and physical features. Simon Weaver takes such biasness as biological racism and argues, "Biological racism was a racism that divided populations through the use of phenotypical, biological or physical traits and led to the formation of racist boundaries between populations" (419). In the past, black people were immensely suffered by the racist attitudes of white. They created fences and separated blacks from their locality. Such visible-invisible boundaries and fences between black and white were the outcome of white hegemony, which was strategically erected for the authentication of white supremacy and their unremitting domination against the black people. It is the power holders, who intentionally instilled specific features to the certain groups of people. Both the Tamangs and black people encountered such historical periods when they became victims of power play. Rana's Muluki Ain played a vital role for the marginalization of Tamangs whereas the European colonization and enslavement became the major cause of blacks' predicament. The black skin was interpreted and established as negative that the skin color itself became the major cause of their consistent suffering. In this regard, Milan Hrabovský postulates, "The slave system not only enslaved on the 'coloured' principle, but the black skin was also referred to as something 'deeper' and more fatal" (66). It portrays the colonizers' biasness towards the African people when the white misinterpreted their skin color and associated them with something fatal. Gradually, the European colonizers validated black color as lowly and physically and psychologically inferior. In Nepal, the Tamangs were taken as inferior in terms of their intelligence. There are still some common opinions and jokes that harshly humiliate and inferiorize the Tamang community. For instance, when they mess up something, people unhesitatingly spew their judgment: "bhoteko buddhi!" ("Bhote's brain!"). The black people and the Tamangs share the similar pain of unremitting domination and marginalization under the existing sociopolitical structure.

The Hindu caste hierarchy had placed the Tamangs in the lowest category: they were just an inch above the so-called impure untouchable castes. In fact, they were slaves, who were not even allowed to write their caste. In the past, they had to raise a 
voice and write an application to the rulers to get back their caste. In this regards, Höfer sheds light on their plight as he writes, "A decree signed by King Tribhuwan and the Rana prime minister Bhim Samser lays down that, instead of the hitherto employed designations Lama and Bhote, hence-forth the designation 'Tamang' from among the caste of the Bhote (12 Tamang Jatika Bhoteko jat) [The caste of Tamang as the caste of Bhote] shall not be called Lama (or) Bhote in documents... but shall be called Tamang" (125). It explicitly presents the hegemony of the rulers, who hold such a powerful position that they could easily snatch away or return back the castes to the certain communities. It clarifies the fact that the Tamangs were immensely exploited under the Hindu rulers who were slaves, but rather different to the African slaves. However, both were associated with the low and inferior social position. As a result, their distinct characteristics were overshadowed and they were viewed as just a piece of flesh. In this context, Hrabovsky's views on the idea of "blackness" aptly matches with the idea of "Tamangness" as he argues, "Blackness is still the main "criterion" of a "lower" origin. . .. the meaning of black as negation, death, bad nature, and even illness" (85). Such a negative interpretation about the certain community reifies the biased and malicious nature of power blocs rather than the inherent truth about the subjects. Virginia Mapedzahama and Kwamena Kwansah-Aidoo accept Hrabovsky's opinion that is related to the negative interpretation of blackness; however, they envision blackness is not merely about skin color, rather it is a social construct persistently conceived as an opposite of whiteness and inferior other (1). Thus, the blackness is the construction loaded with negative attributes and misinterpretation. Amid such dark and negative portrayal, the blackness turns to be burdensome. Mapedzahama and Kwansah-Aidoo's research on the black African diaspora's experience in Australia has unveiled the blackness as burden since the blackness never fades in the background, it cannot be hidden, but it is hyper-visible (8). The hyper-visibility of blackness and negativity attached to the color have become a burden to them. The Tamangs are also visible like the black people due to their phenotypic cues, specifically, their flat nose and slanting eyes are quite distinct. The Mongolian look does not come under the Nepali beauty standard, which values tall nose and wide eyes. Nonetheless, the indigenous communities' aesthetic values, beauty and ethnic knowledge have been continuously under the discussion among the intellectuals these days. Kailash Rai, Amrit YonjanTamang and Usha Kala Rai are some of the representative figures from indigenous community, who have consistently raised their voice and emphasized on the ethnic aesthetic values and knowledge. Nevertheless, both Tamangs and black people share immense sufferings caused by misinterpretation despite their physical and geographical distance.

However, after the 2006 Democratic Movement, many marginal communities have developed certain consciousness about their position in the Nepali society. Most of the peripheral groups including the Tamang community have started to raise their voices. The historical event of 2006 has clicked the consciousness of people as it made a favorable environment for everyone to raise a voice for their space in the mainstream economic, social, cultural and political activities. Consequently, the Tamang intellectuals, including the poets have started collectively raising their dissenting voice through their writings.

\section{Tamangness in the Tamang Poems}

The Tamangness intrinsically signifies the identity of Tamang community, which gets intelligible through their culture, values and language. The Tamang people have to struggle hard to claim their identity. Several historical documents have validated 
the systematic domination and marginalization of the Tamang community. However, the new socio-political consciousness implanted by the 2006 Democratic Movement has played a vital role among the Tamangs to raise their voice. The movement has an impact on the identity issues of indigenous communities. For instance, the Tamang poets have started raising their voice in their poems.

Laxmi Rumba's "Primordial Rhythm" depicts the bitter reality of fearsome history that has smashed and wounded primeval dreams of indigenous communities. The rulers snatched away their smile, peace and land from them. They invaded their colorful states and killed many Tamang rebels that forced them to leave their ancestor's land. The Tamang community's dense population in the outskirts of the Kathmandu valley like Swyambhu, Boudha and Budhanilkantha areas verifies their past connection with the capital. Rabindra Tamang postulates that some of the stone scriptures of Malla rulers hint towards the ancient Tamang state in Kathmandu (21). The Hindu caste system was one of the reasons for marginalization of Tamangs. For instance, the Tamangs were not allowed to use their caste in their names. In fact, they were highly intimidated, coerced and silenced by the dominating new rulers. Abhi Subedi's view aptly matches with the reality that they had suffered. He claims that the indigenous voice was silenced and even they were not allowed to use their language (24). As a result, the Tamang community has always remained away from the powerful socio-political position. Rumba portrays the same reality in her poem as she recalls the troublesome past:

A fearsome history

dripping down the portico,

washed away numerous colorful states.

Erased all the countless faces

close to Rinjen Dorje.

The dictatorial step

obstructed roads of primal faces. (Trans. is mine)

It is said that Tamang King Rinjen Dorje and his people came under the conspiracy of the Hindu rulers and were brutally killed. After that, gradually, the ancient Tamang states and history were washed away. Now, they are struggling to get back their lost voice and identity. The identity issue has become more sensitive after the 2006 Democracy

Movement. The Tamang community has started voicing for their space like never before. Rumba threatens the atrocious authority and claims for their definite downfall when their Darjyu ("colorful flag") will flutter freely:

Yambu's power gets slitted

within the skewer of its own dream.

While the pain exceeds its limit,

along with Damphu's primordial rhythm,

there flutters free Darjyu. (Rumba; Trans. is mine)

Rumba portrays a painful history of Tamang ancestors through the portrayal of massacred character like "Rinjin Dorje." However, cultural tropes like Damphu (“a musical instrument") and Darjyu have intensified her rebellious voice for identity and freedom. Rumba's choice of cultural symbols and apt narratives have properly evoked the idea of Tamangness.

Muktan Theba has depicted his boiling anger against the power blocs in his poem "Angi and Aairak Pong" ("Aunt and a Pot of House Wine"). The Hindu rulers' dominating attitude towards the indigenous groups has taken his peace of mind. Whenever he visits Kathmandu, he gets mocked by his own ancestor's disturbing past. When he flips history pages, he finds immense sufferings of his forefathers. His father's social status as a porter and his grandmother's "blood smeared petticoat" unfold 
tremendous exploitation on them. Even he loses his temper. He portrays his pain and anger pointing towards the history of injustice and mistreatment against the Tamang community. He writes about his past in the following lines:

For the first time

While climbing up the steps of dharahara

I have witnessed

The skulls of my aakkhes

Hanging on the wall.

Alongside were hanging

blood smeared petticoats

of my virgin grandmother. (30-32; Trans. by Theba)

Theba presents a dreadful history of exploitation and suppression of the Tamang community. In the past, the Hindu rulers denied the Tamangs from any prestigious job and dumped them to be the porters or non-official servants in the army. Additionally, many Tamang women were brought in the Rana's palaces for their service. As Susane Asman posits, "Tamang men were recruited on these hunting trips. They managed the tents and worked as guards and porters. During these trips, Tamang women were employed and brought directly back to Kathmandu with the court procession" (40). The innocent Tamang women became a part of a nanigunj or a rakhel ("the mistress") to Ranas at the courts. Obviously, nobody asked for their consent; they were treated as slaves. While recalling the repressive past of their ancestors, the Tamang writers get more aggressive. Theba projects his resentment and pain together in his poem. Even though their grandmothers and grandfathers were helpless in front of the existing sociopolitical structure, today's Thebas are conscious enough to raise their voice against injustice and biasness of the power holders. Both Rumba and Theba have un-curtained the hidden dark past along with their resisting voice and claimed for the Tamang identity.

The Tamang community is harshly suffered by the deceits and dominations of the Gorkhali ruler Prithivi Narayan Shah. Different researches have substantiated the inhuman power play of Shah. In this context, Rajkumar Dikpal points out that Shah's military troop had deceitfully murdered Timal's Tamang King Rinjin Dorje calling him for peaceful meeting without weapon (qtd. in Bhandari 40). Several narratives and oral history about Timal (Tamang state) also hint for the guileful downfall of King Rinjin Dorje. Later, the concept of Hindu kingdom and the Hinduization process have intensely affected the ethnic identity and the Tamang culture. However, the oppressive and painful past could not leave the community in peace. As a result, their anger, discontent and resistance are expressed in the form of creative writings. Muktan Theba's poem "Mother and Fire" captures the rebellious consciousness of a Tamang mother. Even though the speaker in the poem is an innocent woman, she reveals her typical alertness towards her condition. It seems as if she wants a radical change and revolution in the society for their equality and freedom. The poet writes:

Yes, my mom never revolted

Silently bore the pains

But my mom

Never let the fire extinguished from her fireplace

Never refused to give the fire to the expectants

Some days ago uncle Gunjaman came

And asked my mother the fire

Offering the fire on his hand she said, 
"Never let this fire to go out Maila [The second son]" (30-32; Trans. by Theba) The poet has presented an indigenous mother, who without being conscious of revolution is the voice of resistance: she has instigated her rebelliousness through her words and act. Her regular duty of saving fire in her hearth points towards her revolting and resisting mind. She not only kindles fire, but also she gives it to other peoples, which directly connects with her cultural awareness, transferring to the younger generations. In this poem, Theba has used the word 'fire,' a powerful symbol of dissidence, which becomes intense since it is preserved by the mother to handover to the fire-searchers. In the epitome of cultural awakening, it is important for the Tamang community to claim their share, space and identity like the poet has anticipated in his poem.

\section{Tamangness and the Use of Cultural Tropes}

Culture covers a wider range of ways of life such as food, costumes, rituals, songs, languages and so on. Like many other cultural groups, the indigenous groups of people have also their own ways of life. In this sense, Hikmat Singh takes culture as a "community act" (12). Every caste groups' behavior and their typical ways of dealing with their life highlight their cultural existence. The cultural behaviors of Tamangs get projected in their everyday normal activities as well. The Tamang poets have lucidly presented the Tamangness through the use of cultural tropes and lively experiences in their poems. Poets like Rawat, Raju Syangtan and Phulman Bal have highlighted the Tamangness through musical instruments, selo dance and cultural dresses, which are important symbols of their cultural identity.

Raju Syangtan's "Chyangba's Wish" ("Tamang Youth's Wish”) satirically depicts general trends of young Chyangbas' wish of going Yambu ("Kathmandu") and settling down there. However, he has emphasized a bitter reality of innocent Tamang youths being trapped by the Yambu's mainstream culture and language that snatch away all of their cultural identities from them. The poet indirectly points out towards Hindu King Mahendra's nationalism that has prioritized the concept of a single identity (the same language and dress). In this connection, Prayag Raj Sharma claims, "The Hindu domination of politics set the real tone for the Sanskritisation process. . . . The powerful instrument used by these Hindus to extend communications across the various culturallinguistic barriers that was their language, Nepali” (144). The Hindu rulers, politicians and administrators together set a strategic net for indigenous communities and compelled them to adopt the Nepali language and culture. Consequently, many marginalized ethnic groups have already become strange to their own mother tongues, cultures, costumes and songs. Syangtan satirizes the dominating mainstream rulers who tactically wiped away the Tamang cultural identity.

Chyangba! don't worry,

even if you can't buy anything there.

Yambu itself will purchase you.

When it invests on you,

it will ask your heart,

It demands for your eyes,

and then your tongue.

Not only that,

it will also ask your Bakkhu, Cap, Damphu, and even the small bird on your Damphu.

After that,

you will be metamorphosed to

a modern Chyangba. (Trans. is mine) 
King Mahendra's concept of a single Nepali identity has accelerated the process of Hinduization and Sanskritization that turned quite intimidating for Chyangbas. Chyangba, who is a representative character of the Tamang community, has mingled and become part of the single identity concept that was imposed by the Hindu rulers. Thus, Chyangba has lost his dress, musical instruments and many other cultural values of his life. Syangtan portrays a bitter reality of cultural domination over the Tamang community. But, at the same time, his honest revelation of the plight of Chyangba could be an eye-opening narration for the community so that they get inspired for the acknowledgement of their own cultural and ritual aesthetics.

The rituals and performativity practiced by the Tamang people remain at the heart of their culture. They express their happiness, sorrow and different emotions through music and dance. In fact, music and dance play an important part to exhibit the Tamang cultural identity. Sirjana Tamang emphasizes the importance of performative rituals of Tamangs and argues that performance is not merely an art of dance, song or just a performance for the sake of entertainment, but it is a portrayal of the distinct living pattern of the Tamang community and their ideologies as a whole (2). As she claims, Tamang dances and songs unfold the whole cultural aspect as well as the ways of life they live in. In this sense, every life is a package of cultural heritage. Similarly, Rawat criticized the power blocs for their domination and glorifies the Tamangness in his poem "A Capital away from Yours." The poem satirically expresses its resistance against the Hindu rulers who thrashed away the indigenous peoples from their ancestor's land and compelled to remain around the surrounding hills of the Kathmandu valley. Nevertheless, Dolmas (young girls) and Chyangbas have built their own places, preserved their cultures and are happily settled down over there. Now, when they view the valley from their elevated residing places, the towers look really tiny and lowly. The poet celebrates the Tamang identity and challenges the powerful valley.

O, Dolma!

Take from your legendary pub

A draught of chhyang,

\section{and come out;}

let's dance- you and I...

Let's scream out to the world:

"We are the master and mistress

of this place;

we also have a capital, as you do. (Rawat 60-62; Trans. by Poudyal)

Rawat depicts a strong sense of cultural inclination as well as raises the voice of resistance against the rulers who dominated and exploited them. They are aware of their ancestors, land and culture that they have now started boasting on and glorifying their own cultural assets. Moreover, they have also threatened the dominating power centers through their writings. The poet has presented chhyang ("rice wine") as a strong cultural symbol to celebrate the Tamangness that points out towards the aggression of Chyangba who has just got drunk. The poem also highlights the revolt of the Tamang community who have built their own abode above the capital despite being thrown away.

The democratic movements have not been properly materialized several dreams of the minority groups in the country, yet since many caste, community and groups are struggling in the margin. Victor Turner names such a separate and marginal state as "liminality" (89). Though Turner has used liminality in the ritual context to describe the transitional phase where people get separated from the group for a certain time. After a specific time, they enter into the reincorporation phase when everybody mingles. In the 
context of Nepal, the indigenous groups are continuously in the liminal phase; they are in the margin, in between and in the ambiguous state. The Tamang community as one of the marginal subjects has attended a long liminal phase and now they are in urgency of reintegration. As a result, they have started voicing for their identity. Phulman Bal talks about the necessity of reintegration to become one of the colors of cultural rainbow in the primeval land. The poet asserts for Tamang's identity not being isolated from the mainstream culture, but being one of the colors of the musical rainbow. He unveils his wishes in the following lines:

I only wanted,

to add a colorful melody

to the single song

you've been singing for centuries.

In a way,

rainbow exists with seven colors

In a way,

music echoes with seven tunes

Similarly,

I only wanted to sing

a colorful song of time. (Trans. is mine)

The way each color in the rainbow carries its own importance as it adds beauty and aesthetic value to the rainbow, every country could achieve peace, happiness and prosperity if there is cultural integration among different communities. Bal claims for the space and searches for the Tamangness within the same structure. He presents "rainbow" and "seven tunes" as symbols of togetherness and beauty to express his desire for a strong bonding with each other.

The critical analysis of the aforementioned poems has validated the fact that the contemporary Tamang poets have asserted the Tamangness in their poems. They have portrayed it as cultural tropes to explore the issues of identity and dissidence.

\section{Conclusion}

The paper has critically analyzed the Tamangness in the contemporary Tamang poems, focusing on the issue of Tamang identity and their resistance. The selected poems by Laxmi Rumba, Muktan Theba, Raju Syangtan, Rawat and Phulman Bal have been undertaken for rhetorical analysis. The poems have expressed dissenting voice of the poets, claiming the space, share, equality and freedom in their ancestors' land.

The political movements after 1990 have ignited the indigenous people's consciousness that radically transformed the socio-political scenario as well as the ways people analyze history. Against this backdrop, the Tamang writers have started raising voices for their rights. They have resisted against the Hindu-based rulers who have dominated the indigenous communities in Nepal. The Tamang community's rich cultural assets including the unique food, typical costumes and mother tongue are overshadowed by the hegemonic mainstream culture. Each marginal community has attempted to revive their cultural aesthetic and claimed for their space in the mainstream society. The findings of the study showed that the contemporary Tamang poets have asserted the Tamangness through their cultural symbols such as their musical instruments, costumes, drinks and language.

Most of the peripheral communities such as indigenous peoples, Madhesis, Muslims, and Dalits have started questioning the power blocs about their washed away history and underprivileged conditions. They have moved forward with their resisting voices and high spirits to claim their lost spaces. For instance, the Tamang poets have 
evoked the Tamangness as cultural tropes in their works to portray cultures, values and beliefs of the Tamang people, questioning their own marginalized position even after the democracy has been restored and the new constitution has been promulgated in the country.

\section{Works Cited}

Asman, Susanne. Bombay Going: Nepali Migrant Sex Workers in an Anti-Trafficking Era. Lexington Books, 2018.

Bal, Phulman. "Rainbow Song." Translated by Kumari Lama, 2020, unpublished.

Dikpal, Raj Kumar. Adhibasi Bidrohako Itihas ("The History of Indigenous Rebellion"). Manjari Publication, 2076 BS ("2019-2020").

Höfer, András. The Caste Hierarchy and the State in Nepal. Himal Books, 2004.

Hrabovský, Milan. "The Concept of 'Blackness' in Theories of Race." Asian and African Studies, vol. 22, no. 1, 2013, pp. 65-88.

Lama, Chakka Bahadur and Dipendra Rokaya. "Karnalika Janajati ra TinkaWastawikta ("The Indigenous Peoples of Karnali and Their Reality")." Samridhha Karnaliko Dukkha ("The Pain of Prosperous Karnali"), edited by Somat Ghimire and Tika Battarai, Sangrila Books, 2072 BS ("2015-2016”).

Syangtan, Raju. "Chyangba's Wish." Translated by Kumari Lama, 2020, unpublished. Malla, Kamal P. The Road to Nowhere. Jagadamba Prakashan, 2015.

Mapedzahama, Virginia and Kwamena Kwansah-Aidoo. "Blackness as Burden? The Lived Experiences of Black Africans in Australia." Sage Open, July-September 2017, pp. 1-13. https://doi.org/10.1177/2158244017720483.

Rawat. "A Capital away from Yours." A Capital Away from Yours, translated by Mahesh Poudyal, Phoenix Books, 2013, pp. 60-62.

Rumba, Laxmi. "Primordial Rhythm." Translated by Kumari Lama, 2020, unpublished.

Sharma, Prayag Raj. The State and Society in Nepal: Historical Foundations and Contemporary Trends. Himal Books, 2004.

Singh, Hikmat. Samaj ra Sanskriti ("Society and Culture"), edited by Ninu Chapagain, Sahasrabdi Publishing, 2060 BS ("2003-2004”).

Subedi, Abhi. "Samakalin Nepali Kabitama Janajatiya Chetana. ("Indigenous Consciousness in Contemporary Nepali Poems")." Pragya Samakalin Nepali Kabitabimarsh ("Poetic Discourse of Academic Nepali Contemporaneity"), edited by Amar Giri, Poudel and Gautam, Nepal Pragya Pratistha, 2072 BS (“2015-2016").

Tamang, Sirjana. “Tambas' Role for Social Harmony: Reading Tamang Marriage Ceremony." MA thesis, Central Department of English, Tribhuvan University, Kirtipur, Nepal, 2018.

Tamang, Rabindra. Prachin Tamang Rajya: Ek Aitihasik Adhyan ("Ancient Tamang State: A Historical Study"). Yamburi Book Point, 2012.

Theba, Muktan. "Aunt and a Pot of House Wine." Akhanda Alap, translated by Muktan Theba, Sangrila Books, 2075 BS , pp. 30-32.

Turner, Victor. "Liminality and Communitas." The Performance Studies Reader, edited by Henry Bial, Routledge, 2008, pp. 89-97.

Weaver, Simon. "Jokes, Rhetoric and Embodied Racism: A Rhetorical Discourse Analysis of the Logics of Racist Jokes on the Internet." Ethnicities, vol. 11, no. 4, 2011, pp. 413-435.

Yonjan-Tamang, Amrit. Nepal Bahiraka Tamang Wangmaya ("Tamang Literature in the Diaspora"). Yamburi Book Point, 2012. 
The Tamangness as a Cultural Trope: A Rhetorical Analysis 76

---. Tamang Sahityako Itihas ("History of Tamang Literature"). Nepal Pragya Pratisthan, 2068 BS (“2011-2012”).

\section{To cite this article [MLA style]:}

Lama, Kumari. "The Tamangness as a Cultural Trope: A Rhetorical Analysis of

Works by the Tamang Poets." SCHOLARS: Journal of Arts \& Humanities, vol. 4, no.

1, February 2022, pp. 65-76. NepJOL, doi:10.3126/sjah.v4i1.43056. 